\title{
School-reopening impact on traffic-induced noise level at different land uses: a case study
}

\author{
M. R. Monazzam $\cdot$ E. Karimi $\cdot$ P. Nassiri • \\ L. Taghavi
}

Received: 3 May 2014/Revised: 6 December 2014/Accepted: 15 February 2015/Published online: 9 April 2015

(C) Islamic Azad University (IAU) 2015

\begin{abstract}
Reopening of schools is usually associated with increased urban traffic and is likely to exacerbate trafficinduced noise level in metropolitan cities. This study was performed to investigate the role of reopening of schools on noise level in one of the most crowded districts of Tehran City. For this, two different noise criteria of LAeq $_{10 \min }$ and SPL were measured during working days at three occasions of morning, noon, and evening in summer (school holiday season) and autumn (reopening season of schools in Iran). According to the results, the average equivalent sound pressure level was $72.3 \mathrm{~dB}(\mathrm{~A})$ in summer and $72.9 \mathrm{~dB}(\mathrm{~A})$ in autumn. The $P$ value of 0.44 obtained from $t$ test indicated that there is no significant difference between the equivalent sound pressure level of the holiday and reopening seasons in the district. Further, the value of the indices Traffic Noise Index, Noise Impact Index, and noise pollution level was constant within both seasons studied. This may be due to the rigid surface of the passages such as asphalt pavement, and high-rise buildings, as well as the facade of buildings that can gradually overshadow the role of school-induced traffic on noise pollution in metropolitan cities.
\end{abstract}

\section{R. Monazzam}

Department of Occupational Hygiene, School of Public Health and Center for Air Pollution Research (CAPR), Institute for Environmental Research (IER), Tehran University of Medical Sciences, Tehran, Iran

E. Karimi $(\bowtie) \cdot$ L. Taghavi

Department of Environment and Energy, Science and Research Branch, Islamic Azad University, Tehran, Iran

e-mail: kelham842@gmail.com

P. Nassiri

Department of Occupational Health School of Public Health, Tehran University of Medical Sciences, Tehran, Iran
Keywords Equivalent sound pressure level $\cdot$ School reopening $\cdot$ Traffic noise $\cdot$ Land use

\section{Introduction}

Traffic flow in cities, particularly crowded areas, is intensive and uneven; moreover, registered noise levels usually exceed allowable limits (Bazaras et al. 2008). Outdoor traffic noise, for those residential buildings adjacent to heavy traffic roads, is the main source that affects the quality and health of indoor acoustic (Zhisheng et al. 2007). A steady growth in traffic congestion has led city planners to seriously consider the resulting environmental impacts, such as traffic noise, accidents, and air pollution (Husted Rich and Nielsen 2007). As an important environmental concern, traffic noise assessment is ubiquitous in many communities, especially for those located near major roadways (Barboza et al. 1995).

There are available several different computational, graphical, and computer modeling techniques and methods to estimate noise levels resulting from roadway traffic (Barboza et al. 1995). As such, Dai et al. (2014) presented an inland waterway traffic noise prediction model to predict noise level in China. The model includes parameters traffic flow, vessel speed, distance from the center of the inland waterway to the receiver, position and height of the barriers and buildings, location of the receiver, type of ground, percentage of soft ground cover within the segment, and water surface conditions. Alam et al. (2006) reported the level of traffic-induced noise pollution in Sylhet City. They suggested that schools should be located about $60 \mathrm{~m}$ away from the roadside. Weber et al. (2014) used landscape metrics to show that the noise level in the city of Leipzig in Germany depends on the properties of the urban structure. 
The results of a study in Jordan indicate traffic congestion, traffic speed, honking, number of lanes, lane width, road slope, and street pavement as important factors influencing noise level in urban areas (Juang et al. 2010). In addition, according to the research in Macau, it was shown that the areas with old urban fabric, narrow streets, complicated road network, and large number of crossroads lead to reduced traffic congestion and thus mitigated noise pollution (MacKenzie and Galbrun 2007). In a noise mapping plan implemented in Taiwan City in 2009, the spatial characteristics of the urban environment noise were analyzed using the noise maps produced at 345 noise monitoring stations. Noise data were collected in various intervals in the morning, afternoon, evening, as well as in winter and summer. According to the obtained results, the highest (69.6 dBA) and the lowest (59.3 dBA) noise levels were occurred in summer mornings and winter evenings, respectively. It was also found that $90 \%$ of the population in Taiwan City is exposed to unaccepted noise levels ( $\mathrm{Di}$ et al. 2005). As the literature reveals, urban fabric and seasons are among influential factors affecting the equivalent sound pressure level in cities.

School-related traffic congestion in and around school sites is among the most important problems of the modern world caused by vehicles, including school transport services and parents' car, vehicles of school authorities (La Vigne 2007). Other factors such as physical infrastructure, street layout, and traffic signs and signals surrounding a school could make school-related traffic even worse (La Vigne 2007). Most of the relevant studies focus on the impact of street noise pollution on students' learning functionality at schools, so that the impact of reopening of schools on noise pollution has totally been neglected. Accordingly, the present study was conducted, for the first time in Iran and abroad, to address the impact of reopening of schools on traffic-induced noise at different land uses in District 14, Tehran City, in summer and autumn 2012. Despite the small area of the district, it is one of the most densely populated areas in Tehran and, according to the 2006 census, includes a total population of approximately 445138 people.

\section{Materials and methods}

The measurements were taken at two seasons of summer (as closure season of schools) and autumn (as reopening season of schools in Iran). For this, a total number of 91 stations were selected randomly in a way to include different land uses, including residential, recreational, educational, commercial, and commercial-residential areas. A handheld sound level meter (B\&K Type 2336) was used to measure equivalent sound pressure level at 10-min time interval. At the same time, geographic coordinates of the measurement points were recorded using Global Positioning System (GPS) (model: HCX VISTA Garmin) and used later to generate the point map of the stations by geographic information system (GIS). In school holiday season, measurements were taken during the weekdays except for Thursday and Friday, at three occasions of morning (7-9 a.m.), noon (1-3 p.m.), and evening (5-8 p.m.).

The measured values were analyzed using SPSS 16.0.

The Traffic Noise Index (TNI) was calculated according to the methodology developed by Longdon and Scholes in 1986 (Pedersen and Halmstad 2003). Besides, the noise pollution level (NPL) value was determined in accordance with the formula provided by Vesilind et al. (1994) (Eggermont 2014). Moreover, Noise Impact Index (NII) was calculated according to the guideline presented by Bies and Hansen (2005). Subsequently, a table was created in Excel software in which descriptive information of the stations, including name and code, longitude and latitude, daily LAeq $_{10 \mathrm{~min}}$, land use, and passage type, was recorded to precede spatial analysis process using Arc GIS (Eggermont 2014). The same procedure was kept to measure $\mathrm{LAeq}_{10 \mathrm{~min}}$ in autumn.

\section{The NII}

To investigate the effect of noise in the environment, the number of exposed people should also be involved. This is provided by the Total Weighted Population Index abbreviated as TWP (Bies and Hansen 2005).

$$
\begin{aligned}
& \mathrm{NII}=\frac{\mathrm{TWP}}{\sum_{i} P_{i}} \\
& \mathrm{TWP}=\sum_{i} W_{i} P_{i}
\end{aligned}
$$

where $P_{i}$ is the number of exposed individuals related to the weighting factor, and $W_{i}$ is noise life damages in accordance with $l_{\mathrm{dn}}$ presented in Table 1 .

\section{Results and discussion}

In order to compare the equivalent sound pressure level of working days and weekends, the Leq values measured at intervals of 10,15, and 30 min were compared using $t$ test. According to the $P$ values of the different intervals $(0.15$, 0.21 , and 0.29 ), no significant difference was found between the mentioned variables within the working days and weekends. Further, the equivalent sound pressure level of working days was investigated in intervals of 10,15 , and 30 min using one-way ANOVA test. The $P$ values of 0.52 , 0.62 , and 0.73 revealed the fact that there was no 
significant difference between the measured values at different time intervals. The one-way ANOVA test was also used to compare the equivalent sound pressure levels at three occasions of morning, noon, and evening. According to the $P$ values of $0.2,0.62$, and 0.11 , there was found no significant difference between the Leq of different occasions. The $P$ value of 0.50 revealed no significant difference between the Leq of different time intervals of 10,15 , and $30 \mathrm{~min}$.

Figures 1 and 2 depict spatial changes in $\mathrm{LAeq}_{10 \min }(\mathrm{dB})$ in summer and autumn seasons, respectively. Spots in the red zones illustrate the highest $\mathrm{LAeq}_{10 \mathrm{~min}}(\mathrm{~dB})$ where the noise pollution level is high. Moving toward the yellow and green zones, the level of noise pollution is reduced. The

Table 1 Values of $l_{\mathrm{dn}}$

\begin{tabular}{lc}
\hline Range of $l_{\mathrm{dn}}(\mathrm{dB})$ & $\mathrm{W} 1$ \\
\hline $35-40$ & 0.01 \\
$40-45$ & 0.02 \\
$45-50$ & 0.05 \\
$50-55$ & 0.09 \\
$55-60$ & 0.18 \\
$60-65$ & 0.32 \\
$65-70$ & 0.54 \\
$70-75$ & 0.83 \\
$75-80$ & 1.20 \\
$80-85$ & 1.70 \\
$85-90$ & 2.31 \\
\hline
\end{tabular}

green spots in the center of the noise map indicate lower noise pollution level in July. In the autumn noise pollution map, due to blocked streets leading to the Imam Ali highway which is under construction, green spots are moved forward the margins of the highway.

As the obtained results indicate, the $\mathrm{LAeq}_{10 \mathrm{~min}}$ values in summer and autumn were $72.3 \mathrm{~dB}(\mathrm{~A})$ and $72.6 \mathrm{~dB}(\mathrm{~A})$, respectively. In other words, there is a difference of about $0.6 \mathrm{~dB}(\mathrm{~A})$ between the $\mathrm{LAeq}_{10 \mathrm{~min}}$ values of the summer and autumn.

For greater certainty, the average LAeq ${ }_{10 \text { min }}$ of both seasons were compared using $t$ test. The $P$ value of 0.44 suggests that there is no difference between the LAeq $10 \mathrm{~min}$ of the seasons.

Table 1 provides a comparison between the average equivalent sound pressure level of different land uses in summer and autumn. The obtained results revealed that the equivalent sound pressure level in autumn is slightly higher than that of in summer in all land uses, except for the commercial land use. The difference between the average LAeq $_{10 \min }$ values in different land uses in both seasons was compared using the paired-samples $t$ test, and the results are briefly presented in Table 2 . As the table suggests, all of the $P$ values are higher than 0.05 , indicating no significant difference between the variables measured.

Comparison between the average $\mathrm{LAeq}_{10 \mathrm{~min}}$ levels in different parts of the street network in District 14 is given in Table 2. As the table suggests, the average $\mathrm{LAeq}_{10 \mathrm{~min}}$ in autumn (reopening season of schools) is higher than that of in summer, in all areas except for the bystreets.
Fig. 1 Spatial changes in LAeq $_{10 \min }$ of the district in summer (*CR stands for commercial and residential land use)

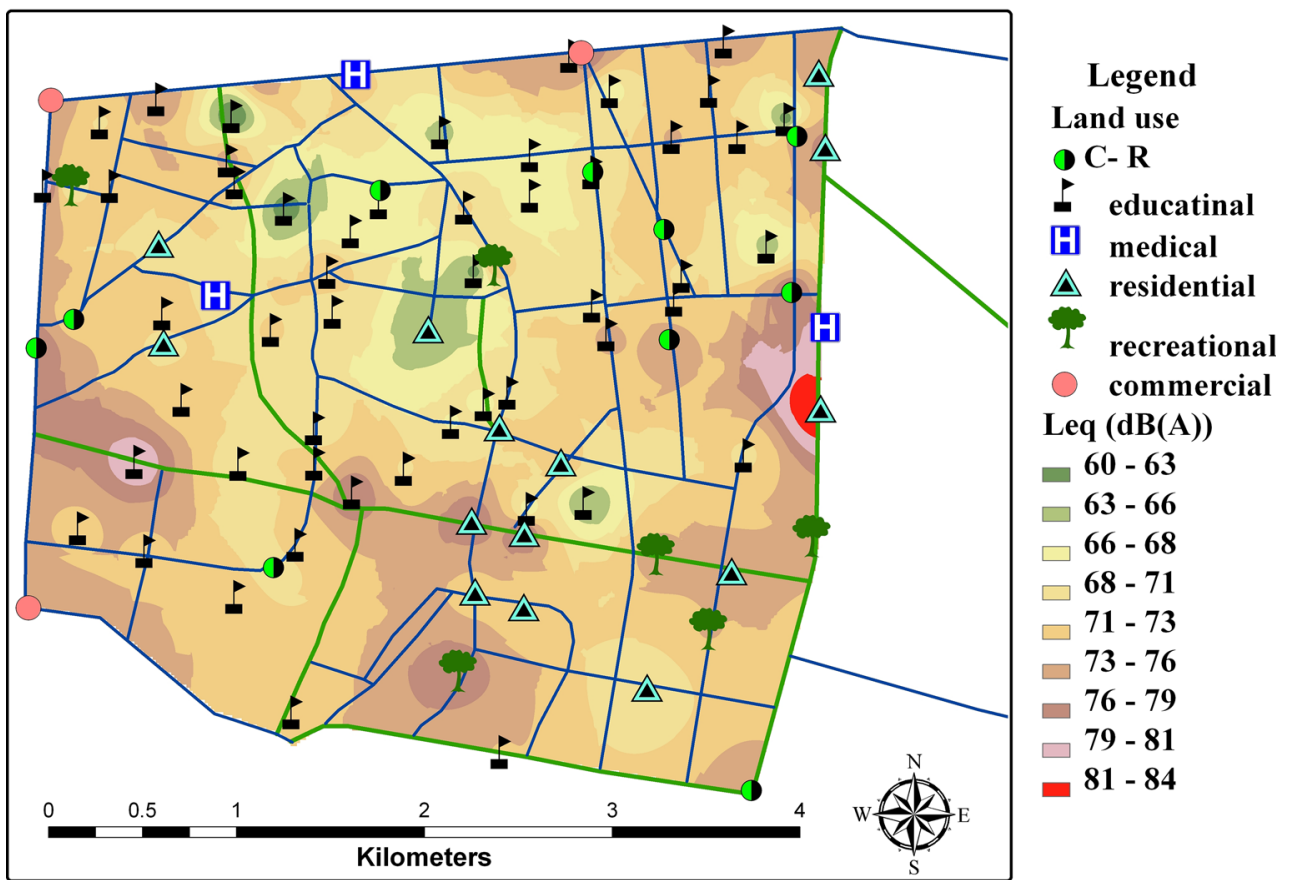


Fig. 2 Spatial changes in LAeq $_{10 \mathrm{~min}}$ of the district in autumn $(* \mathrm{CR}$ stands for commercial and residential land use)

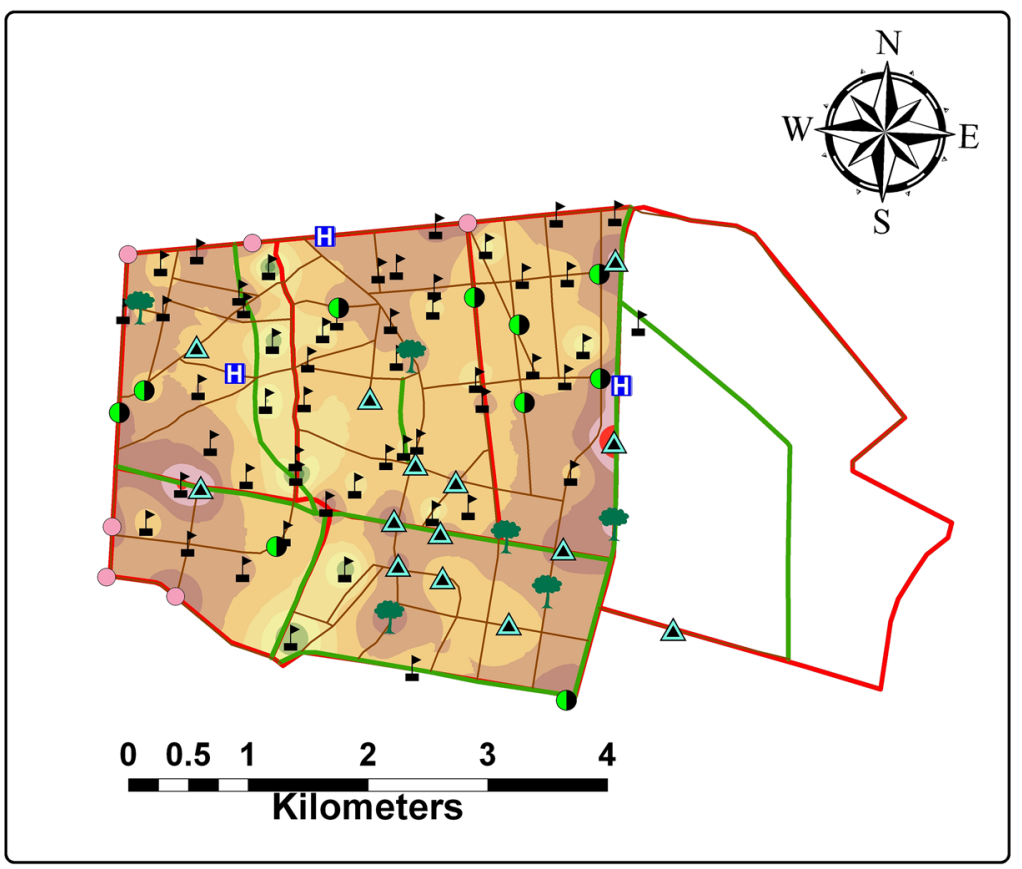

\section{Legend}

Land use

I educational

H medical

$\triangle$ residential

recriational

commercial

- C-R

$\operatorname{Leq}(\operatorname{dB}(A))$

$58-60$

$60-63$

$63-66$

$66-69$

$69-72$

$72-75$

$75-78$

$78-81$

$81-84$
Table 2 Comparison of the average LAeq $_{10 \text { min }}$ values in different land uses in summer and autumn

\begin{tabular}{llll}
\hline Location & $\begin{array}{l}\mathrm{LAeq}_{10 \min } \\
(\text { summer }\end{array}$ & $\mathrm{LAeq}_{10 \mathrm{~min}}$ (autumn) & $P$ value \\
\hline Educational & 70.9 & 70.9 & 0.11 \\
Recreational & 73.9 & 74.5 & 0.53 \\
Medical & 63.6 & 64.5 & 0.57 \\
Residential & 74.3 & 75.1 & 0.27 \\
Residential-commercial & 73.9 & 74.1 & 0.81 \\
Commercial & 77.8 & 76.8 & 0.19 \\
\hline
\end{tabular}

Low level of noise pollution in autumn is due the fact that Imam Ali highway was under construction in that season, during which many bystreets leading to the highway were blocked. In other words, the difference in the traffic-induced noise level could not be attributed to the reopening of the schools. The paired-samples $t$ test was used to compare the average LAeq $_{10 \mathrm{~min}}$ values in different types of passages (Table 3). The $P$ value in Table 3 shows no significant difference between the variables.

Figures 3 and 4 depict the deviation of $\mathrm{LAeq}_{10 \mathrm{~min}}$ levels from permissible standard levels in summer and autumn, respectively. As the figures present, no significant difference was observed between the seasons except for the Pirouzi Street and Basij Expressway.

Table 4 provides a comparison between the NII values in summer and autumn. This index is used to assess the impact of noise level on exposed people. The NII with a value of 1.5 denotes that the noise pollution level is above the residents' tolerance threshold in this district that can
Table 3 Comparison of the average $\mathrm{LAeq}_{10 \mathrm{~min}}$ values at different land uses in summer and autumn

\begin{tabular}{llll}
\hline $\begin{array}{l}\text { Street } \\
\text { network }\end{array}$ & $\begin{array}{l}\text { LAeq }_{10 \min } \\
\text { (summer) }\end{array}$ & $\begin{array}{l}\text { LAeq }_{10 \min } \\
\text { (autumn) }\end{array}$ & $P$ value \\
\hline Highway & 77.9 & 79.2 & 0.17 \\
Main street & 71.8 & 73.2 & 0.08 \\
Intersection & 75.5 & 75.7 & 0.34 \\
Bystreet & 67.9 & 65.1 & 0.46 \\
Square & 71.6 & 72.4 & 0.49 \\
\hline
\end{tabular}

cause citizens' complaint. The NII values show no difference between two seasons.

The average TNI values in summer and autumn were 81.29 and $80.71 \mathrm{~dB}$, respectively. There was found no significant difference between the TNI values in two seasons $(P$ value $=0.75)$. The average NPL was $83.98 \mathrm{~dB}$ in summer and $84.29 \mathrm{~dB}$ in autumn. No significant difference was observed between the NPL values in two seasons $(P$ value of 0.70$)$.

The main strength of this research is to investigate, for the first time, the impact of school reopening on traffic-induced noise level in cities. The findings highlight the role of urban fabric on variations of equivalent sound pressure level and introduced it as more determining factor on noise pollution in cities, compared to the school reopening. It would be better if this study could be performed at a larger scale so as to provide more accurate results due to the larger statistical population. Moreover, more reliable comparing results would be achieved if the study was performed 
Fig. 3 Deviation of LAeq 10 min values from the permissible standard limit $[\mathrm{dB}(\mathrm{A})]$ in summer $\left({ }^{*} \mathrm{CR}\right.$ stands for commercial and residential land use, and SD refers to standard deviation)

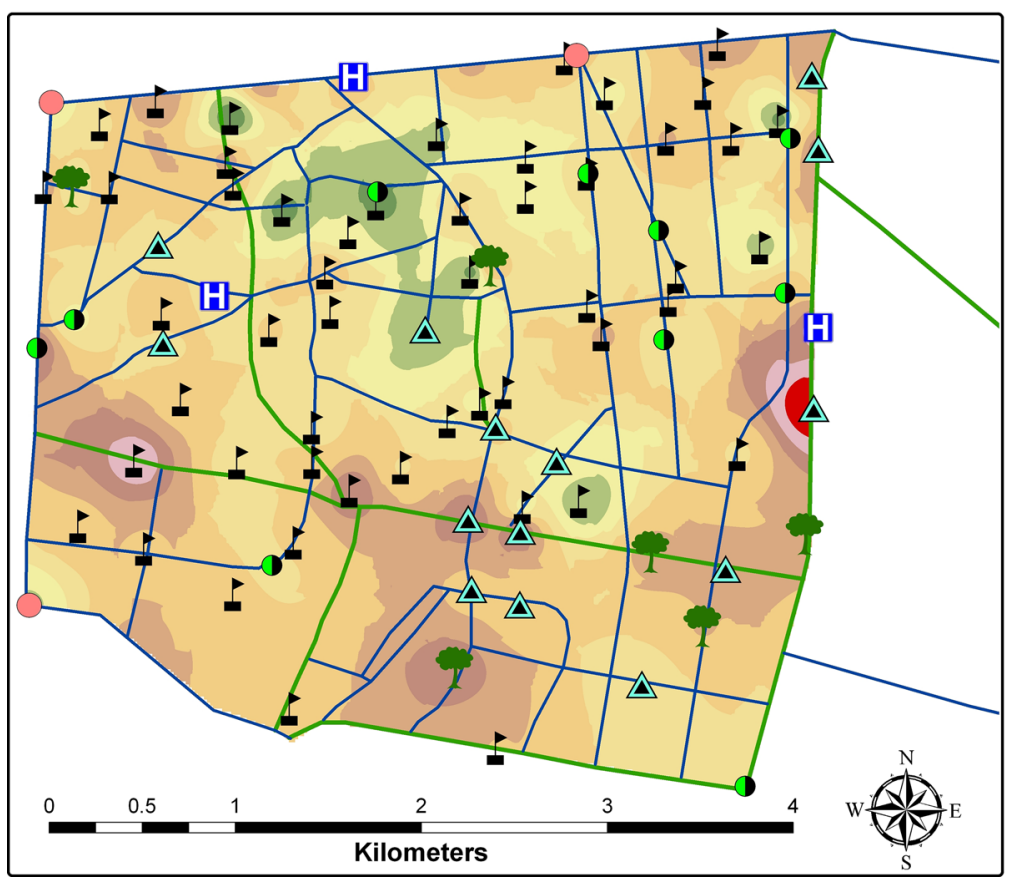

Legend

Land use

C- $\mathbf{R}$

- educatinal

H medical

$\triangle$ residential

recreational

commercial

SD*

$5-8$

$8-11$

$11-13$

$13-16$

16- 18

$18-21$

$21-23$

$23-26$

$26-29$
Fig. 4 Deviation of LAeq $_{10 \mathrm{~min}}$ values from the permissible standard level $[\mathrm{dB}(\mathrm{A})]$ in autumn $(* \mathrm{CR}$ stands for commercial and residential land use, and SD refers to standard deviation)

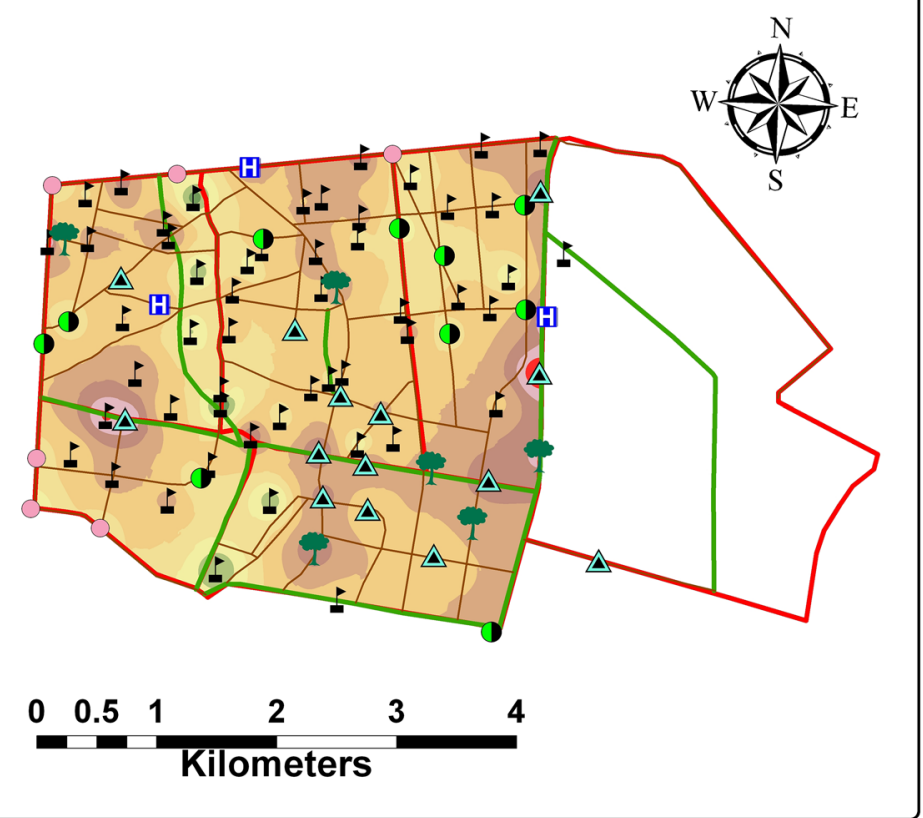

Legend

Land use

I educational

it medical

$\Delta$ residential

- recriational

- commercial

C-R

$\mathrm{SD}^{*}$

3 - 5

$5-8$

8 - 11

11-14

14-17

17- 20

20 - 23

23 - 26

26- 29 simultaneously in two regions with different urban fabrics of old and modern. The $P$ value of 0.44 indicates no significant difference between the average sound pressure levels of summer and autumn. The NII that represents noise harmfulness was constant at 1.5 in both seasons, without any variation. There was found no significant difference between the average values of TNI and NPL in summer and autumn. It verifies the fact that traffic congestion caused by school reopening cannot affect noise pollution level in the district.
Moreover, current modifications in the urban fabric of Tehran overshadow the impact of traffic-induced noise. Among the current modification in the urban fabric of the district can be pointed to the increased height of the structures and increased use of reflective materials in the building facade, including marble, granite, glass, and composite sheets (metal-like sheets). This can increase sound reflection and prevent sound propagation (Eggermont 2014). The role of urban fabric on increased noise level was emphasized by 
Table 4 Comparison of the NII in summer and autumn

\begin{tabular}{|c|c|c|c|c|c|c|}
\hline Region & $\begin{array}{l}\text { LAeq } \\
(\max ) \\
\text { autumn }\end{array}$ & $\begin{array}{l}\text { LAeq } \\
(\max ) \\
\text { summer }\end{array}$ & $W$ & Pop & WP & NII \\
\hline 1 & 80.2 & 80.5 & 1.7 & 102,758 & $174,688.6$ & 1.5 \\
\hline 2 & 78.8 & 79.2 & 1.2 & 130,047 & $156,056.4$ & \\
\hline 3 & 84.4 & 84.2 & 1.7 & 100,079 & $170,134.3$ & \\
\hline 4 & 81.9 & 80.8 & 1.7 & 61,554 & $104,641.8$ & \\
\hline 5 & 78.7 & 78.2 & 1.2 & 50,700 & 60,840 & \\
\hline
\end{tabular}

Ismail (2014). He studied geometric parameters of the dense Islamic urban texture on the resultant noise levels. Tang and Wang (2007) showed that the urban forms in historical areas with narrower roads, complex road networks, and a higher density of intersections lead to lower traffic congestion and consequently lower noise pollution. Montalvão Guedes et al. (2011) declared that the physical characteristics of the urban shape, including construction density, the existence of open spaces, and the shape and physical position of buildings have a significant influence on environmental noise.

\section{Conclusion}

The role of school reopening in increased traffic-induced noise level in urban environments is an important issue that has received little attention. The public perception is that the impact could be significant. However, the findings of this study contradict this hypothesis. According to the results, it was found that the impact of the reopening of schools on equivalent sound pressure level would be negligible. It is important to mention that traffic congestion cannot be as much important as virtual sources of noise. The rigid surfaces such as asphalt, concrete, stone, or mosaic pavements, the facade of buildings, the height of buildings, and the width of the streets are among the virtual sources of noise pollution overshadowed the role of traffic congestion in Tehran. Nowadays, the number of virtual sources is greatly being increased in Tehran. This number could be even greater in the future if the current trend continues.

The noise mitigation strategies in the district should focus on limiting the virtual sources in the district. The use of sound-absorbing materials in asphalt pavement could be another important preventive strategy. It is highly recommended expanding soft surfaces throughout the city by increasing green spaces and arboriculture. Dense planting of a mixture of broadleaves and conifers (such as acacia and sycamore) in the city could be a proper noise control strategy.

Acknowledgments The authors would like to express their grateful thanks to Mrs. Hoseini at GIS Department of Municipality of Tehran,
District 14, for his sincere contribution toward implementing the present study. Special thanks to Mr. Kaveh Aghamiri and Dr. Amir Hossein Javid who helped us in this project.

\section{References}

Alam JB, Jobair Bin Alam M, Rahman MM, Dikshit AK, Khan SK (2006) Study on traffic noise level of Sylhet by multiple regression analysis associated with health hazards. Iran J Environ Health Sci Eng 3(2):71-78

Barboza MJ, Dee PE, Paul Carpenter Sh, Roche LE (1995) Prediction of traffic noise: a screening technique. J Air Waste Manag Assoc 45(9):703-708. doi:10.1080/10473289.1995.10467398

Bazaras J, Jablonskyte J, Jotautiene E (2008) Interdependence of noise and traffic flow. Transport 23(1):67-72. doi:10.3846/16484142.2008.23.67-72

Bies DA, Hansen CH (2005) Engineering noise control, theory and practice. Spon Press, Taylor \& Francis Group, London and New York, pp 172-173

Dai B, He Y, Mu F, Xu N, Wu Zh (2014) Development of a traffic noise prediction model on inland waterway of China using the FHWA. Sci Total Environ 482-483:480-485. doi:10.1016/j. scitotenv.2013.06.019

Di GQ, Zhang BJ, Shang Q (2005) Subjective annoyance caused by indoor low-level and low frequency noise and control method. J Environ Sci (China) 17(1):135-140

Eggermont JJ (2014) Chapter 3-Neural substrates of noise-induced hearing loss. In: Noise and the Brain. Academic Press, Elsevier

Husted Rich J, Nielsen OA (2007) Assessment of traffic noise impacts. Int $\mathrm{J}$ Environ Stud 61(1):19-29. doi:10.1080/ 0020723032000113790

Ismail MRA (2014) A parametric study of the effect of building distributions and size on the propagation of sound in the urban environment. J Archit Eng Technol 3:118. doi:10.4172/21689717.1000118

Juang DF, Lee CH, Yang T, Chang MC (2010) Noise pollution and its effects on medical care workers and patients in hospitals. Int $\mathrm{J}$ Environ Sci Technol 7(4):705-716. doi:10.1007/BF03326180

La Vigne N (2007) The problem of traffic congestion around schools. Problem-Specific Guides Series, No. 50, U.S. Department of Justice, Office of Community Oriented Policing Services

MacKenzie DJ, Galbrun L (2007) Noise levels and noise sources in acute care hospital wards. Build Serv Eng Res Technol 28(2):117-131. doi:10.1177/0143624406074468

Montalvão Guedes IC, Bertoli SR, Zannin PHT (2011) Influence of urban shapes on environmental noise: a case study in AracajuBrazil. Sci Total Environ 412-413:66-76. doi:10.1016/j. scitotenv.2011.10.018

Pedersen E, Halmstad H (2003) Noise annoyance from wind turbines-a review. Swedish Environmental Protection Agency Report 5308

Tang UW, Wang ZS (2007) Influences of urban forms on trafficinduced noise and air pollution: results from a modelling system. Environ Model Softw 22(12):1750-1764. doi:10.1016/j.envsoft. 2007.02.003

Vesilind PA, Peirce JJ, Weiner RF (1994) Enviromental Engineering. Butterworth-Heinemann

Weber N, Haase D, Franck U (2014) Traffic-induced noise levels in residential urban structures using landscape metrics as indicators. Ecol Indic 45:611-621. doi:10.1016/j.ecolind.2014.05.004

Zhisheng L, Dongmeia L, Sheng M, Guoqiang Zh, Jianlong L (2007) Noise impact and improvement on indoors acoustic comfort for the building adjacent to heavy traffic road. Chin J Popul Resour Environ 5(1):17-25. doi:10.1080/10042857.2007.10677482 